\section{Back to Ivermectin: Is History Repeating Itself?}

Sir,

Ivermectin, a FDA-approved and popular anti-parasitic agent, has been used against mild novel coronavirus disease 2019 (COVID-19). It has demonstrated efficacy in the prophylaxis and treatment of COVID-19 patients. The evidence, so far, is based on in-vitro studies. The literature found is in pre-print form. Ivermectin is a cheap agent with safe side effect profile. It prevents viral and hosts proteins from entering into the host cell nuclei. ${ }^{1}$

Reported data has shown convincing evidence of ability of ivermectin in reducing viral load in patients of COVID-19. Early administration of ivermectin was shown to be effective in early viral clearance and reduced duration of symptoms in patients with mild COVID-19. It was found as inhibitor of SARS-CoV-2 replication in the laboratory. ${ }^{1}$

Ivermectin has been in use for both parasitic and bacterial infections in the developing countries; and is effective and affordable. The 5-day course of ivermectin costs US $\$ 1.80^{1,2}$ and is readily available; hence, it may be considered an attractive alternative forCOVID-19 treatment.

Investigators at the University of Navarra Clinic and Barcelona Institute of Global Health published a pilot study, which showed efficacy of drug in reducing viral load, disease duration, and in stopping its transmission. ${ }^{2}$ It also deliberated on a fact that despite two proven vaccines, protecting people globally to stop viral spread, will take at least two years; hence, treatment options are needed focusing on COVID-19 infection. Ivermectin was studied as an agent reducing viral transmission, when given within the first five days of symptom onset. ${ }^{3,4}$ Another study from Bangladesh, a randomised, double blind, placebo controlled trial, conducted to find out rapid viral clearance with the use of ivermectin, showed early viral clearance in the 5 -day ivermectin treatment $\mathrm{arm} .{ }^{5}$ A retrospective study in 2020 found that ivermectin reduced mortality when compared with azithromycin and hydroxychloroquine. ${ }^{5}$

Ivermectin is being used in Latin-American countries, despite lack of convincing evidence of its efficacy. ${ }^{3-5}$ The study subjects were given one single dose of ivermectin or placebo to 24 patients with confirmed mild symptoms within first 72 hours. No difference was found in the PCR-positive patients. The mean viral load in the ivermectin-treated group was three times lower at 4 days and 18 times lower at 7 days after treatment. ${ }^{3}$ The difference found was not statistically significant. Reduced duration of symptoms, such as loss of smell and taste and cough, was found.
Another study conducted at Pasteur Institute observed similar findings in terms of reduced viral loads, symptom duration, and antibody levels; and warranted larger studies with patient diversity. ${ }^{4}$ Robust randomised controlled clinical trials of ivermectin in COVID-19 treatment are needed to validate these important findings.

\section{CONFLICT OF INTEREST:}

The author declared no conflict of interest.

\section{AUTHOR'S CONTRIBUTION:}

SS: Solely drafted and edited the manuscript.

\section{REFERENCES}

1. Pandey S, Pathak SK, Pandey A, Salunke AA, Chawla J, Sharma A, et al. Ivermectin in COVID-19: What do we know? Diabetes Metab Syndr 2020; 14(6):1921-2. doi: 10.1016/j.dsx.2020.09.027.

2. Chaccour C, Ruiz-Castillo P, Richardson MA, Moncunill G, Casellas A, Carmona-Torre $\mathrm{F}$, et al. The SARSCoV-2 ivermectin navarra-isglobal trial (SAINT) to evaluate the potential of Ivermectin to reduce COVID-19 transmission in low risk, non-severe COVID-19 patients in the first 48 hours after symptoms onset: A structured summary of a study protocol for a randomized control pilot trial. Trials 2020; 21(1):498. doi: 10.1186/s13063020-04421-z.

3. Rizzo E. Ivermectin, antiviral properties and COVID-19: A possible new mechanism of action. Arch Pharmacol 2020; 393(7):1153-6. doi: 10.1007/s00210-020-01902-5.

4. Schmith VD, Zhou JJ, Lohmer LRL. The approved dose of ivermectin alone is not the ideal dose for the treatment of COVID-19. Clin Pharmacol Ther 2020; 108(4):762-5. doi: 10.1002/cpt.1889.

5. Alam MT, Murshed R, Bhiuyan E, Saber S, Alam RF, Robin RC. A case series of 100 COVID-19 positive patients treated with combination of ivermectin and doxycycline. J Bangladesh Coll Physic Surg 2020; 38:10-15. doi: 10.3329/jbcps.v38i0.47512.

Sadaf Sheikh

Department of Emergency Medicine, Sultan Qaboos University Hospital, Muscat, Oman

Correspondence to: Dr. Sadaf Sheikh, Department of Emergency Medicine, Sultan Qaboos University Hospital, Muscat, Oman

E-mail: sheikh.sadaf@gmail.com

Received: January 24, 2021; Revised: March 06, 2021;

Accepted: March 11, 2021

DOI: https://doi.org/10.29271/jcpsp.2022.02.274 